\title{
Transumanismo e o futuro (pós-)humano
}

| ${ }^{1}$ Murilo Mariano Vilaça, ${ }^{2}$ Maria Clara Marques Dias |

Resumo: O transumanismo é uma controversa perspectiva de investimento na transformação da condição humana. Visando ao melhoramento biotecnológico da natureza humana, ele protagoniza o debate acerca do futuro (pós-)humano. Na base da concepção transumanista está o investimento na biotecnociência como um modo de Iluminismo humanista de raízes biológicas. O objetivo do artigo é analisar o debate sobre o futuro da humanidade. Para tanto, apresentamos a perspectiva transumanista, ressaltando definições, características, valores e principais argumentos, analisando o conceito de natureza humana, pois ele é fundamental na polarizada discussão travada entre os transumanistas e bioconservadores. Nossas principais conclusões apontam para a impertinência dessa polarização, bem como do uso do conceito de natureza humana e pós-humano para esclarecer o tema do melhoramento humano. Assim, cumpre despolarizar o debate e apostar otimista e prudentemente no futuro biotecnológico.

Palavras-chave: transumanismo; natureza humana; pós-humano; biotecnologia; melhoramento humano.

\footnotetext{
1 Escola Politécnica de Saúde Joaquim Venâncio, Fundação Oswaldo Cruz; Programa de Pós-Graduação em Educação, Gestão e Difusão em Biociências, Universidade Federal do Rio de Janeiro. Rio de Janeiro-RJ, Brasil. Endereço eletrônico: contatoacademico@ hotmail.com

2 Programa de Pós-Graduação em Filosofia e Programa de Pós-Graduação em Bioética, Ética Aplicada e Saúde Coletiva, Universidade Federal do Rio de Janeiro. Rio de Janeiro, Brasil. Endereço eletrônico: mcdias1964@gmail.com
}

Recebido em: 21/04/2013 Aprovado em: 11/04/2014 


\section{Era biotecnológica: preâmbulos de um futuro (pós-)humano}

É relativamente consensual que uma erabiotecnológica se aproxima (FUKUYAMA, 2002; LECOURT, 2003; BOSTROM, 2005c; JOTTERAND, 2010). Savulescu (2009) prevê que, em um futuro cenário de desenvolvimento biotecnológico, aquele que será instaurado com o progresso tecnológico no século XXI, alterarse-á um dos mais tradicionais dilemas da moralidade. Em vez de enfrentarmos a questão de que atitudes e deveres morais temos para com os seres compreendidos, atualmente, como animais não humanos (por exemplo, gato, cachorro, cavalo, etc.), a questão será que obrigaçôes teremos com outro tipo de não humano, isto é, os chamados pós-humanos.

Para Savulescu (2009), pós-humana é uma dentre outras formas de vida, caracterizada por "seres originalmente 'evoluídos' ou desenvolvidos a partir de seres humanos, mas significativamente diferentes, de tal modo que não são mais humanos em qualquer aspecto significativo" (p. 214). Tal estágio seria alcançado através da aplicação de técnicas de manipulação, instrumentalização e artificialização da vida, do patrimônio biológico do humano, acarretando uma mudança de estatuto especista. Quer dizer, o humano, por iniciativa própria e com vistas ao melhoramento da sua natureza, deixaria de ser humano.

Esse hipotético futuro cenário pós-humano instituído pela revolução biotecnológica tem despertado entendimentos, reações e sentimentos opostos. Dentre outras discordâncias, enquanto uns defendem que a condição pós-humana será o resultado mais promissor do real poder beneficente da biotecnociência, pois ela representaria o ápice do melhoramento humano, outros temem que o seu eventual poder maleficente comprometa radical e incontornavelmente a natureza humana e tudo que, tradicionalmente, tem sido fundamentado nela.

Tal questionável dualismo de perspectivas sobre as consequências do melhoramento humano por vias biotecnológicas tem caracterizado um dos mais importantes debates no campo da ética aplicada (BOSTROM; SAVULESCU, 2009). Assim, o futuro da humanidade tem sido perspectivado através de uma problemática e obscurescente oposição binária de tipo "bem versus mal". De acordo com Bostrom e Savulescu (2009), já se delineia uma linha divisória biopolítica entre aqueles que são pró-melhoramento - ou anti-anti-melhoramento, conforme Buchanan (2011) -, os transumanistas, e aqueles anti-melhoramento, 
os bioconservadores. Segundo os autores, em linhas gerais, aqueles "acreditam que uma ampla gama de melhorias deve ser desenvolvida e que as pessoas sejam livres para usá-las para transformar-se de maneira completamente radical"; estes, por sua vez, "acreditam que nós não devemos alterar substancialmente a biologia ou a condição humana” (BOSTROM; SAVULESCU, 2009, p. 1). Ainda sobre os bioconservadores, Agar (2004) assevera que eles não são conservadores em um sentido tradicional, mas sim em um mais fundamental, pois "ao invés de tentar proteger alguns modos de agir, eles veem-se como protetores tanto da humanidade quanto do significado humano" (p. 18).

Dito de outro modo, ao passo que os transumanistas apostam na superação dos limites da condição humana e na pós-humanidade como uma ampliação das possibilidades de ser no mundo, como se vê em um esquema disponibilizado por Nick Bostrom (2005c), os bioconservadores avocam o papel de defensores intransigentes da natureza humana, ainda que isso implique manutenção daqueles limites. O bioconservador Francis Fukuyama (2002), por exemplo, prenuncia dramaticamente que o futuro pós-humano é um cenário fúnebre e funesto, no qual o humano e seus valores mais básicos desaparecerão, dentre eles, o de direitos humanos. Ou seja, enquanto, para alguns, o processo de alteração da condição humana dará origem a um ser pós-humano, e isso será algo positivo, melhorador, pois beneficiará o humano, para outros, ocorrerá justa e radicalmente o inverso. $\mathrm{O}$ que parece estar em questão - por sinal, de modo indevido - seria quem ameaçaria (lado do "mal") a natureza humana, tentando "melhorá-la", e quem supostamente a protegeria (lado do "bem"), mantendo-a estruturalmente precária.

Há um consenso entre transumanistas e bioconservadores de que as biotecnologias terão um imenso papel em um futuro mais ou menos próximo, estabelecendo um ponto de cesura entre o passado e presente, de um lado, e o futuro da humanidade, de outro (FUKUYAMA, 2002; KASS, 2003; HUGHES, 2004; BOSTROM, 2005b). O recente e detalhado livro organizado por Savulescu, Meulen e Kahane (2011) aborda as últimas tecnologias de melhoramento de capacidades humanas. Sua capa traz uma imagem bastante sugestiva: um homem vitruviano dentro de uma drágea transparente. A ideia de uma produção laboratorial da vida simbolizada pela imagem não é uma fantasia mirabolante de uma mente futurista, mas uma possibilidade tangível. 
De acordo com Jotterand (2010), “o desenvolvimento de biotecnologias emergentes está à beira de redesenhar as fronteiras da existência humana” (p. 617). Interfaces cérebro-computador, extensão radical da vida, neuromelhoradores e membros biônicos são exemplos de biotecnologias que, acredita-se, permitirão ao humano transcender as suas atuais limitações biológicas. Doenças incuráveis e deficiências que impingem dor, sofrimento e limitações funcionais, por vezes incapacitantes, poderiam ser erradicadas, promovendo, assim, a saúde e o bem-estar. Capacidades mentais, corporais, morais e emocionais poderiam ser melhoradas, sendo ampliadas a um nível de eficiência ainda inimaginável. Em tese, melhoraria a qualidade de vida, elevando o nível de bem-estar individual e, quiçá, coletivo.

Parece, então, inquestionável que a humanidade será ainda mais profunda e radicalmente afetada pela ciência e tecnologia (LECOURT, 2003). O que não é um fato - e é bastante questionável, por exemplo, dos pontos de vista biológico e histórico, como argumentaremos à frente -, mas desponta como uma das hipóteses mais desconsertantes para um futuro mais ou menos distante, é que esse recrudescimento da tecnocientificação da vida gerará um futuro pós-humano.

Supondo uma real possibilidade de concretização dessas mudanças, surgiriam questôes, tais como: por que devemos investir nelas? Por que não? Essas mudanças devem ser compreendidas como uma nova etapa, qualitativamente superior, do processo milenar de evolução, ou será o início de um tenebroso fim da espécie humana? Elas derivam de perguntas mutuamente excludentes: o humano será "aperfeiçoado", mas permanecerá humano; ou será um humano, mas "piorado"? O que teremos não será mais um ser humano, mas isso representará uma evolução (um bem, algo positivo); ou o pós-humano será um retrocesso sem precedentes (um mal, algo negativo)?

Estaríamos, então, diante da iminência do fim daquilo que chamamos de natureza humana? Se sim, isso é algo que devemos temer e evitar absolutamente ou no qual, ao contrário, devemos investir irrestritamente? Haveria um "caminho do meio", uma aposta crítica, prudente, mas otimista no futuro humano aperfeiçoado?

Neste artigo, que está dividido em duas seções, abordamos o transumanismo por meio de uma revisão de literatura sobre o tema, ressaltando e debatendo alguns dos seus principais argumentos, propostas e valores, tendo em vista o futuro da 
natureza (pós-) humana. O artigo está dividido em duas seções. Na primeira seção,

salientamos algumas definições desenvolvidas por alguns dos seus precursores e por alguns dos seus atuais expoentes, identificando e debatendo pontos centrais do pensamento transumanista. Na segunda, analisamos o conceito de natureza humana, cotejando os argumentos dos bioconservadores e dos transumanistas, a fim de problematizar os usos feitos por ambas as vertentes, buscando mostrar que ele é inadequado para amparar tanto uma postura tecnofóbica quanto uma tecnoprofética. Por fim, a título de conclusão, criticamos a polarização do debate, bem como a hipótese de um estágio pós-humano, apostando em um futuro biotecnológico pautado por uma postura otimista-prudente.

\section{Transumanismo e a ideia de melhoramento humano}

A chamada filosofia transumanista moderna foi originalmente descrita no ensaio de Max More, intitulado Transhumanism - Towards a Futurist Philosophy, em 1990, no qual o transumanismo é definido como

[...] uma classe de filosofias que busca nos guiar em direção a uma condição pós-humana. Transumanismo compartilha muitos elementos do humanismo, incluindo o respeito pela razão e pela ciência, um compromisso com o progresso e uma valorização da existência humana (ou transumana) 'terrena', em vez de alguma pós-vida sobrenatural. Transumanismo difere do humanismo ao reconhecer e antecipar as radicais alteraçōes na natureza e as possibilidades de nossas vidas resultantes de várias ciências e tecnologias, tais como a neurociência e a neurofarmacologia, o prolongamento da vida, nanotecnologia, ultrainteligência artificial, combinado com uma filosofia racional e um sistema de valores (MORE, 1990).

Quanto à organização de um movimento transumanista, o final da década de 1990 tem especial importância. Em 1997, David Pearce e Nick Bostrom criaram o WTA/H+ (World Transhumanist Association/Human plus), atualmente denominado de Humanity ${ }^{+}$ou Humanity Plus. De acordo com Pearce (2011), a associação foi uma consequência fortuita de um manifesto (The Hedonistic Imperative) divulgado por ele na internet, em 1995. Nele, Pearce apresentou uma defesa do uso das biotecnologias para abolir toda forma de sofrimento não só entre humanos, mas em todo o mundo vivente (PEARCE, 1995). Bostrom, motivado pela leitura do manifesto, sugeriu a criação de uma espécie de "organização guarda-chuva" para congregar os transumanistas. Em 1998, eles publicaram a primeira versão de Declaração Transumanista. 
More (1990) também define o transumanismo como um processo perpétuo de superação dos limites do humano, com um emprego escrupuloso da razão, da ciência, da lógica e do pensamento crítico, tendo por base os seguintes princípios: expansão ilimitada, autotransformação, otimismo dinâmico, tecnologia inteligente, inteligência crescente, ordem espontânea, liberdade, prazer e longevidade.

Anders Sandberg define o transumanismo como uma filosofia de que podemos e devemos nos desenvolver a níveis mais elevados, física, mental e socialmente, usando métodos racionais (SANDBERG, s/d). Outra definição é fornecida por Jotterand (2010), para quem o transumanismo é mais do que um projeto tecnocientífico, mas também um movimento ideológico, cujos pressupostos estão enraizados na filosofia iluminista. James Hughes (2004), por sua vez, define-o como uma ideia antiga, segundo a qual os humanos podem usar a razão para transcender as limitações da sua condição. Simon Young, um exacerbado entusiasta do transumanismo, afirma que ele é uma crença na superação das limitações humanas por meio da razão, da ciência e da tecnologia, apoiando as tentativas de eliminar doenças, de melhorar o corpo e a mente, e, no limite, superar até mesmo a morte. Ele acredita que, assim "como o humanismo nos libertou das cadeias da superstição, o transumanismo nos livrará de nossas cadeias biológicas" (YOUNG, 2006, p. 32).

Segundo Nick Bostrom et al. (2003), o transumanismo é um movimento vagamente definido, que se desenvolveu nos últimos vinte anos de modo gradativo, promovendo uma abordagem interdisciplinar para compreensão e avaliação das oportunidades para melhorar (enhance) a condição humana, aprimorando seu organismo, ampliando capacidades físicas, mentais e emocionais por meio das biotecnologias disponíveis ou em desenvolvimento.

A Declaração Transumanista estabelece os princípios gerais que orientam o transumanismo. Na versão atual (2009), resultado de modificações em 2002 e 2009, leem-se oito pontos, os quais, em suma, estabelecem que: (1) o humano, já fortemente afetado pela ciência e tecnologia, pode ser ainda mais beneficiado, por exemplo, com a superação do envelhecimento, de deficiências e do sofrimento involuntário; (2) haja vista os riscos das biotecnologias, deve haver um esforço de sua investigação e compreensão, a fim de reduzir riscos e acelerar as aplicações, cujos efeitos sejam benéficos; (3) através da elaboração de políticas, deve-se respeitar os direitos e autonomias individuais, defender o bem-estar de toda 
forma senciente de vida, demonstrando nossas responsabilidades morais com as

geraçôes vindouras; (4) deve-se permitir a vasta disponibilização de um amplo rol de técnicas de melhoramento de suas próprias vidas, associada à liberdade de escolha individual de usá-las ou não.

Calcados em princípios como esses, os transumanistas, ligados ao secularismo, rejeitando argumentos de cunho estritamente religioso, visam a promover uma nova forma de Iluminismo, de cunho biológico. À semelhança do Esclarecimento moderno, o humano deve sair da sua "menoridade biológico-estrutural", corajosamente investindo na autotutoria. Por meio do cálculo racional, ampliando o potencial humano cibernético a um nível superior, o humano, ao mesmo tempo, estaria realizando plenamente a sua "natureza cibernética", a saber, de governar tudo o que há (DUPUY, 2009), e alterando a sua "natureza vulnerável”, retirando aquilo que lhe prenderia à tutoria de uma natureza precária. Quer dizer, há uma dubiedade quanto à relação do humano com distintos traços da "natureza". Mas, em síntese, o humano deveria deixar de, por preguiça ou temor, ser tutorado pela natureza quanto ao seu processo evolutivo, assumindo, então, a responsabilidade de guiar o próprio melhoramento. Assim, a perspectiva transumanista pode ser entendida, de fato, como uma consequência do Humanismo secular e do Iluminismo. A união entre razão, ciência e técnica para um investimento no (pós-)humano justificaria o fato de os transumanistas se autodenominarem humanistas racionais (DUPUY, 2009; YOUNG, 2006).

Costumeiramente, os transumanistas recebem três acusações fundamentais, sendo chamados de anti-humanistas perigosos, pragmáticos sem valores, e ingênuos e inconsequentes tecnoprofetas. Os transumanistas rejeitam a acusação de que seriam desumanizadores, em um sentido negativo, deletério. Ao contrário, se houver alguma desumanização, uma vez que perspectivam o pós-humanismo, isso terá um sentido positivo, beneficente. A partir da(o) ideia/objetivo do "humano mais" (Human Plus), os transumanistas apontam fundamentalmente que as características (biológicas) do humano devem ser alteradas, tornando-o mais "feliz", "saudável", longevo.

Também ao contrário do que vem sendo alardeado, o transumanismo não carece de fundamento, tampouco se pauta numa credulidade tecnocientífica ingênua. No nosso entendimento, para analisá-lo de forma honesta, é mister apresentá-lo como uma perspectiva com um cunho normativo e científico, 
que, apesar de polêmica e questionável, é criteriosa. A tabela transumanista de Bostrom (2005c) comprova isso. Nela, vê-se uma criteriosa hierarquização de valores, que, resumidamente, pode ser descrita assim: valor nuclear ou central (Core Value), condiçōes básicas (Basic Conditions) e valores derivados (Derivative Values). No primeiro plano, defende-se a ideia de que o humano deve ter a oportunidade de explorar as possibilidades do campo pós-humano. Este se baseia, no segundo plano, em certas condições básicas, a saber, segurança global, progresso tecnológico e amplo acesso. Por fim, em terceiro plano, certos valores derivados devem ser observados: a natureza humana pode ser alterada; liberdade morfológica e reprodutiva (a escolha da utilização das biotecnologias é individual); paz, cooperação internacional e pacto de não proliferação de armas de destruição em massa; aperfeiçoar o conhecimento através de mais pesquisas, incentivo do debate público, do pensamento crítico, da quebra de preconceitos, etc.; ampliação da inteligência individual, coletiva e artificial; adoção da perspectiva do falibilismo filosófico, reexaminando constantemente os pressupostos, à medida que as pesquisas e a produção efetiva de novas técnicas avancem; opção pelo pragmatismo e cientificidade; defesa da diversidade (espécies, raças, crenças religiosas, estilos de vida, etc.); preocupação com o bem-estar de toda forma de vida senciente; salvar e prologar vidas.

Contrariando a terceira acusação, Bostrom (2005c) afirma que o transumanismo não implica otimismo tecnológico, pelo menos não em um sentido irrestrito. Danos como o agravamento das desigualdades sociais, o comprometimento das relaçóes humanas, o desaparecimento de culturas podem, de fato, ser causados. Bostrom (2003) entende que, embora as biotecnologias possam gerar benesses, tais como o controle dos processos bioquímicos, o aumento do bem-estar emocional e o incremento da saúde, os transumanistas estão atentos aos riscos, uma vez que

[n] o dark side da questão, os transumanistas reconhecem que algumas dessas tecnologias podem causar grande dano à vida humana, oferecendo riscos até mesmo à sobrevivência nossa espécie. Buscar compreender os perigos e trabalhar para prevenir desastres é parte essencial da agenda transumanista (p. 5).

Embora tais ressalvas indiquem uma ampla gama de preocupações (sociais, religiosas, éticas, políticas, culturais, etc.), a argumentação transumanista prestigia, como ficou evidenciado, o aspecto biológico do humano. Tal opção é coerente, pois é plausível afirmar que a natureza humana, para o transumanismo, 
é basica ou exclusivamente a sua biologia. É a natureza biológica do humano que

está no foco transumanista. Antecipando, mas em resumo, o que será analisado a seguir, o melhoramento humano se dará a partir do melhoramento biológico. Mas será que "tudo" está na biologia, de modo que alguns desafios de outras ordens, tais como as citadas, seriam solucionados biologicamente? Não nos parece. Aliás, é razoável supor que "benefícios" biológicos individuais (por exemplo, extensão da vida de alguns) possam gerar problemas coletivos graves (por exemplo, escassez de suprimentos).

Outra objeção possível refere-se à defesa da diversidade, que é um elemento da lista de Bostrom (2005c), uma vez que haveria uma aparente incompatibilidade entre ele e a ideia de pós-humanismo. Se o transumanismo propugna um estágio superior de desenvolvimento, e isso está fundado no ideário de que a nova espécie (pós-humana) é melhor do que a humana, como coadunar essa visão com a defesa da diversidade, por exemplo, de espécies? Não seria mais coerente supor que a espécie pós-humana será o parâmetro ideal, na medida em que o humano terá um valor inferior relativo ao grau de desenvolvimento?

Hughes (2004) sustenta que, do ponto de vista do transumanismo democrático, o futuro pós-humano deve ser alcançado, observando se as tecnologias emergentes são seguras e disponibilizando-as a todos. Supondo o igual acesso, será que isso, ao invés de "resolver o problema", não criaria um novo, a saber, a escolha de não "se melhorar" não seria compreendida como um equívoco, um erro, o que geraria algum tipo de preconceito contra o humano "não melhorado", como Sandel (2013) sugere? Como serão interpretadas, em um futuro pós-humano, as mazelas sofridas por dado indivíduo que, embora tivesse acesso às biotecnologias, optou deliberadamente por não se modificar? Elas não podem ser social, cultural ou moralmente compreendidas mais como fruto de uma má escolha individual do que como expressão do exercício da liberdade morfológica supracitada? A culpabilização preconceituosa e restritiva do indivíduo que decidiu "manter-se humano" é, para nós, um risco iminente concernente ao melhoramento biológico, pondo em xeque certos valores transumanistas.

Não obstante as implicações ético-políticas do pensamento transumanista, cabe destacar que os transumanistas divergem consideravelmente acerca da obrigação ou não de melhorar-se (VILAÇA; DIAS, 2013; VILAÇA, 2014). Enquanto, por exemplo, Hughes esposa a obrigação de darmos a nossa 
descendência os corpos mais saudáveis e as melhores capacidades possíveis por meio da aplicação da biotecnociência, Sandberg defende a chamada liberdade morfológica (VILAÇA, 2014).

\section{O futuro da natureza humana: humanos melhorados ou não mais humanos?}

De modo esquemático, uma perspectiva moralmente aceitável deve oferecer respostas a pelo menos quatro questōes correlacionadas: o que é o humano; o que é fazer-lhe o bem (ou, promover o seu bem); como fazer-lhe bem (idem); e que futuro os humanos, enquanto indivíduo e coletividade, devem buscar.

O debate em torno do melhoramento humano está enraizado nesse campo de questôes, que envolve a definição de conceitos básicos, especialmente de natureza humana, mas também uma gama de argumentos e valores que derivam deles. Como vimos, os transumanistas apostam na mudança da biologia humana como forma de melhorar o humano. Persson e Savulescu (2010; 2011; 2012), por exemplo, têm defendido o chamado melhoramento moral, pressupondo que alterações em nível cerebral poderão, por si sós, promovê-lo. Alguns bioconservadores, por sua vez, temem a instrumentalização da biologia humana, na medida em que entendem que isso poderia solapar a humanidade e seus valores mais fundamentais (FUKUYAMA, 2002; HABERMAS, 2004). Embora tenham perspectivas opostas, transumanistas e bioconservadores parecem compartilhar um mesmo equívoco: acentuar demasiadamente a dimensão biológica do humano, ao ponto de, por vezes, restringi-lo a ela.

Bioconservadores e transumanistas estão igualmente comprometidos com algum conceito de natureza humana e pós-humanidade (AGAR, 2004). Enquanto aqueles a veem como a essência humana a ser preservada intocada, pois seria a base dos valores humanos mais importantes, estes propugnam, conforme supracitado, que ela pode e deve ser melhorada, a fim de ampliar a perspectiva de florescimento humano, mesmo que isso implique o estágio pós-humano. Tornase patente, portanto, que um dos elementos-chave do debate é a concepção e o valor de natureza (pós-)humana adotados.

A natureza em geral, é vista, por muitos, de um modo quase sacralizado. Bostrom e Sandberg (2009) sublinham a tendência manifesta de se dar preferência às coisas tidas como naturais, em detrimento das artificiais. De 
alimentos a remédios, há uma confiança quase incontestável, ainda que por vezes injustificada, na beneficência da natureza. Daniels (2009), contrariando acertadamente, no nosso entendimento, essa ideia, assevera que há características "boas" e "más" na natureza em geral, bem como na humana, de modo que não há nada de errado, em si, em alterá-las. Se compreendemos essa natural (biológica) suscetibilidade como um mal, alterá-la, visando à sua superação, seria uma forma de promover o bem do humano.

Variadas são as definições existentes, mas há, de acordo com Buchanan (2009), uma definição de natureza humana filosoficamente dominante. Pelo menos desde Aristóteles, a natureza é tida como um "conjunto de características que são comuns a todos os seres humanos e que distingem os humanos de outros tipos de seres" (BUCHANAN, 2009, p. 142). Ele acrescenta que há concepções filosoficamente menos sofisticadas, por exemplo, que “[...] a natureza humana consiste em um conjunto de disposições que todos (ou pelo menos a maioria) os seres humanos têm, assim como uma vasta gama de atividades humanas que dão forma ao comportamento, independentemente do contexto cultural, ao longo da história humana" (BUCHANAN, 2009, p. 142).

Agar (2004) considera que a ideia de preservação do mundo natural, logo, da natureza humana, é mais bem compreendida se analisada num contexto histórico de uma tradição de pensamento encampada por pessoas que condenam qualquer forma de melhoramento não natural, porque estaria usurpando as funções divinas. Para ele, tais pessoas alegam que foi Deus quem criou ("naturalmente") as mentes e corpos humanos, de tal modo que tentar recriá-los melhores em laboratório seria brincar de Deus.

Persson e Savulescu (2010) afirmam que "humano" é uma classificação biológica. Ser humano é, em um sentido básico, fazer parte da espécie Homo sapiens. Há outros sentidos, é claro, tal como humano como o oposto de inumano (cruel, 'sem coração'), o que implica considerar humano como algo, um ser, que tem qualidades morais boas (PERSSON; SAVULESCU, 2010). Há, ainda, a famosa definição de ser humano enquanto ser racional, o que, há muito, tem gerado um sem-número de controvérsias (SAVULESCU, 2009). Para os autores, qualquer que seja a definição de humano, não há nenhuma virtude especial (maior valor) em fazer parte da espécie humana, pois “pertencer à espécie humana” é uma mera contingência, podendo acarretar até mesmo certos prejuízos. 
Não obstante, o humano desenvolveu uma forma de preconceito especista (Human prejudice) sobre si mesmo, traduzido na crença em uma (suposta) especial importância do humano (Special significance) e em um (hipotético) privilegiado estatuto moral (SAVULESCU, 2009), os quais estariam fundamentados, para alguns, nas prerrogativas da sua natureza humana.

Contra tal ideia, Savulescu (2009) examina a concepção filosófica denominada personism - para a qual é moralmente menos importante a noção de ser humano do que a de pessoa - sobretudo a partir de um artigo ${ }^{1}$ do filósofo inglês Bernard Williams, criticando a alegação de que o humano possui privilégios morais perante outros seres pelo mero fato do seu pertencimento especista. Persson e Savulescu (2010), supondo que não há nenhum valor moral especial do humano que esteja fundamentado no pertencimento biológico a uma espécie (Homo sapiens), argumentam que a pesquisa e a terapia biomédicas podem beneficiar o homem, tornando-o mais humano em alguns sentidos bastante relevantes, como no sentido moral, mesmo que ele deixe de ser humano no sentido biológico. Logo, de acordo com alguns transumanistas, a moralidade humana não está fundamentada numa noção abstrata de natureza humana, mas sim na sua dimensão biológica, podendo, inclusive, ser "prejudicada" por esta. Desse ponto de vista, a natureza humana pode e deve ser alterada, pois, ao invés disso gerar prejuízos à humanidade, trará benefícios substantivos.

Os bioconservadores rechaçam esse argumento. Leon Kass, por exemplo, um proeminente bioeticista norte-americano, que presidiu, entre 2001-2005, o President's Council on Bioethics estadunidense, conhecido, e muito criticado também, por fundamentar seus argumentos em princípios religiosos cristãos (AGAR, 2004; BOSTROM, 2005b; PINKER, 2008), diz que nem todos aplaudem a intimação para um futuro pós-humano, tampouco gostam da ideia de recriar o Éden, brincando de Deus (KASS, 2003). Citando as obras de C. S. Lewis (The Abolition of Man), conhecido escritor inglês cristão, e de Aldous Huxley (Brave New World), ele afirma que a promessa futurista de super-humanização deve despertar em nós as mais sérias preocupações acerca das suas consequências para o significado do humano e da moral (KASS, 2003).

Outro ferrenho crítico é Francis Fukuyama. Nomeado, em 2002, para compor o conselho presidido por Kass, Fukuyama (2004) publicou um ensaio intulado Transhumanism, na edição da revista americana Foreign Policy, cujo foco eram 
"[a]s ideias mais perigosas do mundo"2 (The World's Most Dangerous Ideas). Para

esse número, foram convidados oito grandes pensadores, com o objetivo de emitir um alerta acerca das ideias mais destrutivas para os próximos anos.

De acordo com Fukuyama (2004), poucas ideias são tão nefastas quanto as defendidas pelos transumanistas. Consoante Bostrom (2004), há três pressupostos na sua argumentação: (1) existe uma essência humana única; (2) apenas aqueles indivíduos que têm essa essência misteriosa podem ter valor intrínseco e merecem direitos iguais; e (3) as melhorias esposadas pelos transumanistas eliminariam essa essência. Essas ideias estão ancoradas numa acepção do conceito de natureza humana.

Em 2002, Fukuyama já havia investido na defesa da ideia de que a preservação da natureza humana é uma condição sine qua non da promoção do humano, da sua dignidade e dos direitos humanos (FUKUYAMA, 2002). Para ele, ao contrário dos transumanistas, alterar a natureza, superando os seus limites biológicos, transformaria perigosamente o estatuto ontológico humano, comprometendo aqueles valores. Recorrendo aos mesmos escritores e obras usados por Kass, ele defende que há uma íntima conexão entre natureza humana, valores e política. A natureza humana serve de parâmetro para todas as ideias normativas ligadas ao humano, pois, ao lado da religião, ela é o que define nossos valores mais básicos. Fukuyama, ao defender a noção de direitos humanos contra perspectivas pragmatistas e/ou utilitaristas no âmbito biotecnológico, argumenta que tal ideia se baseia apropriadamente na noção de natureza humana.

Consoante Fukuyama (2002), natureza humana é o somatório do comportamento e das características que tipificam a espécie humana, cuja origem são os fatores genéticos, e não os ambientais. Contrariando os argumentos relativistas e construcionistas sociais dos fenótipos - como é o caso do biológo Richard Lewontin, que apela sobremaneira aos fatores ambiental e cultural ele afirma que, embora haja variação de gradiente das características da espécie devido a fatores hereditários e ambientais, há limites máximo e mínimo, e isso é estabelecido pelo genótipo. A estatura é o exemplo utilizado para comprovar a sua tese, pois, ainda que haja anões (limite mínimo) e gigantes (máximo), não há humanos com mais de três metros ou menos de trinta centímetros.

O autor apela à estatística para ajudar a precisar o conceito, afirmando que "a tipicidade é um artefato estatístico - refere-se a algo próximo da mediana de 
uma distribuição de comportamentos e características" (FUKUYAMA, 2002, p. 130) entre os indivíduos. Para ele, ainda que cor de pele e tipo sanguíneo não sejam exemplos de tipicidade, pois variam demasiadamente, fatores como altura, força, traços psicológicos (inteligência, agrassividade e autoestima) seriam, já que se distribuem normalmente em torno de um mesmo ponto mediado em qualquer amostra populacional de humanos. Como não há universais de fato, "desvio padrão zero", quanto mais próximo da mediana dada característica estiver, mais afeita à natureza humana ela será. Em suma, "para uma característica ser considerada universal, ela precisa ter um único e distinto ponto médio ou modal, e um desvio padrão relativamente pequeno" (FUKUYAMA, 2002, p. 135).

Ainda que possamos ver traços religiosos ou cripto-religiosos em bioconservadores como Kass e Fukuyama, há quem defenda a indisponibilidade da natureza humana à artificialização com argumentos seculares, por exemplo, Jürgen Habermas. Para Habermas (2004), a natureza humana é constituída por certas características que conferem ao humano vulnerabilidade e precariedade. Elas servem como firme fundamento para as nossas intuiçóes morais, os nossos vínculos sociais e a nossa autocompreensão ética enquanto espécie, bem como para a autonomia, dignidade e autenticidade humanas. Habermas está especialmente preocupado com os limites daquilo que denomina de engenia positiva da natureza humana interna (DNA). Supondo que esta seja como uma "massa de modelar" suscetível a uma manipulação e design tecnocientíficos e que é a base fundamental daqueles fatores supracitados, programar a sua configuração determinaria aquilo que um sujeito será futuramente, solapando, por exemplo, sua autonomia (HABERMAS, 2004).

De um ponto de vista ou de outro, os bioconservadores amparam-se no conceito de natureza humana, religioso ou secular, para argumentar contra as biotecnologias com fins de seleção e melhoramento humanos. Vejamos, abaixo, como tais argumentos podem ser objetados.

A ideia de natureza humana como características e comportamentos compartilhados pela maioria, defendida por Fukuyama, é problemática. Buchanan (2009) argumenta nesse sentido, mostrando quão antagônicas são algumas das mais recorrentes características tipificadoras do humano - egoísmo; preconceito; insociabilidade; crueldade; amar a descendência e se sacrificar por ela; tolerância; sociabilidade; empatia e moralidade; etc. Daniels (2009) argumenta que a variação 
das características geralmente relacionadas à humanidade é bastante grande entre os indivíduos, para que possamos adotá-las como traços tipificadores da espécie. Afinal, segundo o autor, que natureza humana comum haveria entre pessoas profundamente tímidas "como ratazanas" e pessoas sobremaneira agressivas "como rinocerontes"?

Estendendo esse raciocínio a outro nível, parece um fato que há uma variação de tendências, características e disposições comportamentais não só quando comparamos indivíduos diferentes, mas também um mesmo indivíduo ao longo de sua trajetória de vida. Se até mesmo um indivíduo sofre alterações no decorrer da sua vida, qual manifestação comportamental expressaria a sua "verdadeira" natureza do humano em geral? Se tomarmos a natureza humana como concomitantemente o resultado do maior índice percentual de normalidade e o fundamento da humanidade, os seres que estão abaixo desse índice seriam humanos em que medida? Um ser tido como humano deixaria de sê-lo por possuir uma ou mais características raríssimas à espécie, fora do desvio padrão, ainda que possuísse outras dentro da média? Resta claro que, quanto ao que caracterizaria a natureza humana, não há um critério ou um conjunto deles que seja suficiente para superar uma marcante arbitrariedade eletiva.

A ideia de que a alteração da biologia humana alteraria radicalmente a natureza humana é compreendida, de um modo antagônico, por bioconservadores e transumanistas. Negativamente, para os primeiros, pois os bioconservadores entendem que isso solaparia, desde a origem (genos = genética), a liberdade e autonomia humanas. Positivamente, para os segundos, porquanto os transumanistas defendem que levaria o humano ao estágio pós-humano, sendo capaz de promover e elevar essas capacidades, dentre os benefícios citados alhures.

A essa ideia, Daniels (2009) contrapõe o argumento de que o humano possui, no máximo, uma natureza disposicional e seletiva, expressa pelo trinômio população-disposição-seleção. Destarte, uma alteração do genótipo humano, por si só, não seria capaz de determinar aquilo que o humano será. A natureza de dada espécie depende necessariamente do ambiente no qual está inserida. Aliás, o genótipo humano atual é resultado fortuito de milênios de alterações sucessivas, que não meramente se sobrepuseram, mas concorreram entre si, processo sobre o qual o meio ambiente teve papel destacado.

No tocante à concepção de que a natureza humana é o firme fundamento da moralidade, devendo, por conseguinte, ser presevada, citamos os argumentos de 
Steven Pinker, que tem se manifestado contra algumas posturas bioconservadoras, especificamente criticando aqueles que aduzem argumentos religiosos (PINKER, 2008). Partindo de uma perspectiva factual, e não moral, de natureza humana, ao mesmo tempo em que critica a tese da tábula rasa, ele argumenta que a suposta ausência de algo como uma natureza humana seria insuficiente para concretização de um ideário nefasto (PINKER, 2002). Quer dizer, ainda que os humanos sejam biologicamente desiguais, ideias-males ligadas, por exemplo, ao medo de uma desigualdade radical (inexistência de natureza humana comum), tais como, preconceitos e discriminaçôes, darwinismo social e opressões, eugenia e genocídio, não seriam sustentáveis do ponto de vista moral (PINKER, 2002). Para ele, nossos valores fundamentais não podem ser caudatários de uma suposição factual que pode ser refutada cientificamente a qualquer momento. E, ainda que seja provada a diferença radical entre os humanos, o raciocínio de que isso serve de base para aqueles males não se sustentaria. Em suma, fatos biológicos devem ser distinguidos de valores humanos, estando, ademais, submetidos a estes.

Buchanan (2009) argumenta no mesmo sentido, afirmando que não necessariamente perderemos nossa capacidade de fazer julgamentos sobre o bem, uma vez que o que é bom para nós não guarda relação de identidade com natureza. Isto é, não precisaríamos de uma natureza como parâmetro de correspondência para avaliar se um valor é bom ou não. A natureza serviria, segundo ele, apenas como um indice de restriçôes. Assim, uma nova natureza, pós-humana, forneceria novas restrições, em relação aos quais nossos julgamentos morais seriam refeitos.

\section{Por um debate não polarizado e uma aposta no futuro humano}

Diante de hipóteses e teses parcialmente questionáveis, é prudente analisar os argumentos de bioconservadores e transumanistas, a fim de evitar uma polarização do tipo "bem contra o mal", sedução dualista à qual o debate bioético tem cedido costumeiramente. Pois, ao mesmo tempo em que é necessário criticar a perspectiva de que não cabe ao humano assumir o protagonismo no processo de melhoramento, cumpre analisar se a biotecnociência merece tanto crédito. Isto é, tanto o biocatastrofismo quanto o tecnoprofetismo podem ter visões extremadas, criticáveis e infundadas. 
No tocante às posições analisadas, por um lado, parece-nos inadequado o apelo bioconservador ao conceito de natureza humana para proscrever o uso de biotecnologias para fins de seleção e melhoramento humano, bem como a sua tese de que a alteração da precária constituição biológica humana, que impinge dor e sofrimento a um sem-número de humanos, comprometeria as relações interpessoais e a capacidade de julgamento moral. Por outro, a retórica transumanista fundamentada na ideia de mudança como melhoramento também merece uma atenção crítica, pois alguns dos benefícios que visam a promover podem trazer, em contrapartida, malefícios previsíveis ou não.

Outro ponto crítico que colocaria transumanistas e bioconservadores ante uma mesma objeção refere-se à pressuposição de pós-humanidade. É possível que seja falsa a tese do estágio pós-humano, defendida pelos primeiros e temida pelos segundos (VILAÇA, 2013). Considerando que a natureza humana não é algo estável e imutável, pois, na realidade, tem como uma das suas características fundamentais a mutabilidade adaptativa e evolutiva, não parece imperativo que a alteração de características que tipificariam o humano destruiria a humanidade. A iminência do surgimento de uma nova espécie parece bastante questionável, inclusive do ponto de vista histórico. Entre os séculos XIX e XX, por exemplo, a estatura média da população, em razão de um incremento nutricional, sofreu um relevante aumento. Salvo engano, essa alteração biológica não foi considerada uma ameaça à natureza ou à dignidade humanas; ao contrário, foi interpretada como uma melhora da constituição fenotípica dos seres humanos.

$\mathrm{O}$ investimento secular na vida humana via biotecnologias ratifica isso. As múltiplas alterações sofridas pelo humano, muitas delas tidas como humanizadoras, já vêm produzindo um humano "mais" e "melhor" há algum tempo. Afinal, a expectativa de vida, apenas para citar um exemplo, não para de crescer em sociedades constituídas pelos avanços tecnocientíficos. Cura de doenças antes mortais; terapias que postergam o processo de envelhecimento e seus "males"; técnicas de reprodução medicamente assistida que permitem a ampliação da idade reprodutiva; o uso extensivo dos marca-passos cardíacos, os quais, embora sejam expressão da tão temida interface humano-máquina, não comprometem a humanidade daquele que o usa, pelo contrário, promovem-na, são algumas expressōes inconfundíveis de um melhoramento humano secular. Será, então, que estamos na iminência do surgimento do pós-humano? A 
natureza humana estaria, feliz ou infelizmente, à beira do ocaso? Conforme a argumentação desenvolvida, segundo a qual a natureza humana é um conceito arbitrário, que serve para reunir as características medianas do humano que em dado contexto são mais prestigiadas, entendemos que não. Todavia, ainda que ela fosse alterada substantivamente, de fato, há traços naturais com os quais não convivemos, no mínimo, de modo confortável. Doenças e deficiências, bem como certas características físicas ou psicológicas incomuns, impingem dor e sofrimento não só ao indivíduo, mas à família, de modo que evitá-los por meio da alteração da natureza biológica humana parece-nos ser uma atitude beneficente.

Não obstante, a crença no estágio pós-humano e os argumentos que dela derivam devem ser colocados em questão. Ou bem esse estágio já está em curso, não sendo uma novidade a ser temida ou buscada, ou bem as grandes mudanças que vimos até agora não representaram a transumanização do homem, e seriam, portanto, um indício para que questionemos a ideia de que o pós-humano será um resultado obrigatório dos avanços biotecnocientíficos. Em suma, um dos cernes do debate bioético em tela pode ser algo que mais tem nos desviado de questôes centrais do que nos ajudado a compreender os reais dilemas envolvendo a biotecnociência e as biotecnologias. Segundo Vilaça (2013, p. 46),

o temor ou a esperança de que uma nova espécie será criada geneticamente, em laboratório, merece ser revisto criticamente, pois pode estar enviesando erroneamente o debate. Isto é, o futuro da humanidade deve permanecer mais incerto do que alguns gostariam e menos determinável do que alguns temem.

Concluímos que cabe contestar uma espécie de "pessimismo protecionista", haja vista seu poder de conservar inalterada uma condição humana que impinge dor e sofrimento que poderiam ser evitados. Porém, concomitantemente, é razoável recomendar um otimismo prudente e crítico sobre as biotecnologias, pois não devemos subestimar sua capacidade de produzir males ainda maiores do que aqueles genuinamente capazes de combater. ${ }^{3}$

\section{Referências}

AGAR, N. Liberal eugenics: In: . Defense of human enhancement. Oxford: Blackwell Publishing, 2004.

BOSTROM, N. A history of transhumanist thought. Journal of Evolution and Technology, v. 14, n. 1, p. 1-25, 2005a. 
. In defense of posthuman dignity. Bioethics, v. 19, n. 3, p. 202-214, 2005 b.

. Is transhumanism the world's most dangerous idea?, 2004. Disponível em <http://

www.transhumanisme.nl/oud/Is\%20Transhumanism\%20the\%20Worlds\%20Most\%20 Dangerous\%20Idea.pdf>. Acesso em: 21 abr. 2013.

. The future of humanity. In: OLSEN, J.-K. et al. (Eds.). New waves in philosophy of technology. New York: Palagrave MacMillan, 2009.

. Transhumanist Values. Review of Contemporary Philosophy, v. 4, issue 1-2, p. 87$101,2005 c$.

BOSTROM, N. et al. The transhumanist FAQ, version 2.1, 2003. Disponível em: <http:// www.transhumanism.org/resources/FAQv21.pdf>. Acesso em: 21 abr. 2013.

BOSTROM, N.; SANDBERG, A. The wisdom of nature: an evolutionary heuristic for human enhancement. In: SAVULESCU, J.; BOSTROM, N. (Eds.). Human enhancement. Oxford: Oxford University Press, 2009, p. 375-416.

BOSTROM, N.; SAVULESCU, J. Human enhancement ethics: The state of the debate. In: SAVUlESCU, J.; BOSTROM, N. (Eds.). Human enhancement. Oxford: Oxford University Press, 2009, p. 1-25.

BUCHANAN, A. Beyond humanity? The Ethics of Biomedical Enhancement. Oxford: Oxford University Press, 2011.

. Human nature and enhancement. Bioethics, v. 23, n. 3, p. 141-150, 2009.

DANIELS, N. Can anyone really be talking about ethically modifying human nature? In: SAVUlESCU, J.; BOSTROM, N. (Eds.). Human enhancement. Oxford: Oxford University Press, 2009, p. 25-42.

DUPUY, J-P. O transumanismo e a absolescência do homem. In: NOVAES, A. (Org.). $A$ condição humana: as aventuras do homem em tempos de mutações. São Paulo: Agir, 2009, p. 89-122.

FUKUYAMA, F. Our posthuman future: consequences of the biotechnology revolution. New York: Farrar, Straus and Giroux, 2002.

. Transhumanism: the world's most dangerous idea? Foreign Policy, v. 144, p. 4243, September 1, 2004.

HABERMAS, J. O futuro da natureza humana: a caminho de uma eugenia liberal? São Paulo: Martins Fontes, 2004.

HUGHES, J. Citizen cyborg: why democratic societies must respond to the redesigned human of the future. Cambridge, MA: Westview, 2004.

. The politics of transhumanism, Version 2.0, March 2002. Disponível em: <http:// www.changesurfer.com/Acad/TranshumPolitics.htm>. Acesso em: 23 abr. 2014. 
JOTTERAND, F. At the roots of transhumanism: from the Enlightenment to a posthuman future. Journal of Medicine and Philosophy, v. 35, n. 6, p. 617-621, 2010.

KASS, L.R. (Ed.). Beyond therapy: biotechnology and the pursuit of happiness. New York: Harper Collins, 2003.

LECOURT, D. Humain, posthumain. La technique et la vie. Paris: PUF, 2003.

MORE, M. Transhumanism: toward a futurist Philosophy, 1990. Disponível em: <http:// www.maxmore.com/transhum.htm>. Acesso em: 21 abr. 2013.

MURPHY, T.F. The ethics of impossible and possible changes to human nature. Bioethics, v. 26, n. 4, p. 191-197, 2012.

PEARCE, D. The hedonistic imperative, 1995. Disponível em: <http://www.hedweb.com/ hedethic/hedonist.htm>. Acesso em: 21 abr. 2013.

. Transhumanism 2011, 2011. Interview with Aron Vallinder (Människa plus).

Disponível em <http://www.hedweb.com/transhumanism/overview2011.html>. Acesso em: 21 abr. 2013.

PERSSON, I.; SAVULESCU, J. Getting moral enhancement right: the desirability of moral bioenhancement. Bioethics, v. 17, issue 3, p. 1-8, 2011.

. Moral transhumanism. Journal of Medicine and Philosophy, v. 35, n. 6, p. 656669, 2010.

. Unfit for the future. The need for moral enhancement. Oxford: Oxford University Press, 2012.

PINKER, S. The Blank Slate: the modern denial of human nature. New York: Viking Penguin, 2002.

.The stupidity of dignity: conservative bioethics' latest, most dangerous ploy. In: The New Republic. May 28, 2008. Disponível em: <http://www.tnr.com/article/thestupidity-dignity>. Acesso em: 21 abr. 2013.

SANDBERG, A. Definitions of transhumanism. In: Introductory texts about transhumanism, s/d. Disponível em: <http://www.aleph.se/Trans/Intro/definitions.html>. Acesso em: 21 abr. 2013.

SANDEL, M. Contra a perfeição: ética na era da engenharia genética. Rio de Janeiro: Civilização Brasileira, 2013.

SAVULESCU, J. The human prejudice and the moral status of enhanced beings: what do we owe the Gods?. In: SAVULESCU, J.; BOSTROM, N. (Eds.). Human enhancement. Oxford: Oxford University Press, 2009, p. 211-250.

SAVULESCU, J.; SANDBERG, A.; KAHANE, G. Well-being and enhancement. In:_____. (Eds.). Enhancing human capacities. Oxford: Wiley-Blackwell, 2011. 
TRANSHUMANIST DECLARATION, 2009. Disponível em: <http://humanityplus.

org/learn/transhumanist-declaration/>. Acesso em: 21 abr. 2013.

VILAÇA, M.M. Melhoramentos humanos, no plural. Pela qualificação de um importante debate filosófico. Kriterion, Belo Horizonte, no prelo, 2014.

. Qual natureza humana? Que aperfeiçoamento? Qual futuro? Reflexões em torno do conceito de natureza humana ampliada. Ethic@. Florianópolis, v. 12, n. 1, p. 25-51, jun. 2013. VILAÇA, M.M.; DIAS, M.C. Melhoramento humano biotecnocientífico: a escolha hermenêutica é uma maneira adequada de regulá-lo? Veritas, Porto Alegre, v. 58, n. 1, p. 61-86, 2013.

YOUNG, S. Designer evolution: a transhumanist manifesto. New York: Prometheus Books, 2006.

\section{Notas}

${ }^{1}$ WILliamS, B.A.O. (1996). "The Human Prejudice's" in his Philosophy as a Humanistic Discipline, MOORE, A.W. (Ed.). Oxford: Princeton University Press. Segundo Williams, nós, humanos, podemos concordar que temos um significado especial, mas sem que isso resulte em acreditarmos que temos uma absoluta importância.

${ }^{2}$ Bostrom (2004) oferece uma réplica, na qual afirma que o único perigo real é o bioconservadorismo reacionário, do qual Fukuyama é um representante. Para detalhes, ver <http://www.nickbostrom. com/papers/dangerous.html>.

${ }^{3}$ M.M. Vilaça participou da redação do artigo, revisão de literatura e aprovação da versão final a ser publicada. M.C.M. Dias participou da redação do artigo e da revisão de literatura. 
Transhumanism and the (post)human future Transhumanism is a controversial perspective of the investment in transformation of the human condition. Targeting at biotechnological human nature enhancement, it emerges as one of the protagonists in the debate about the (post)human future. At the base transhumanist conception is the investment on the biotechnoscience as a humanistic iluminism of biological roots. This paper aims to analyze the debate about the future of humanity. To this end, we present the transhumanist perspective, highlighting definitions, characteristics, values, and main arguments, analyzing the concept of human nature, for it is fundamental in the polarized discussion between the transhumanists and bioconservatives. Our main conclusions indicate the impertinence of the polarization, as well as the use of the concept of human nature and post-human to clarify the theme of human enhancement. Thus, we must depolarize the debate and bet optimistically and prudently in the biotechnological future.

Key words: transhumanism; human nature; post-human; biotechnology; human enhancement. 